\title{
Correlação entre a produtividade do feijoeiro no sistema de produção orgâni ca e atributos do solo
}

\author{
Luís F. Stone', Enderson P. de B. Ferreira ${ }^{1}$, Agostinho D. Didonet ${ }^{1}$, \\ Alexandre B. Heinemann ${ }^{1}$ \& Jaison P. de Oliveira ${ }^{1}$
}

\begin{abstract}
RESUMO
Objetivou-se, com este trabalho, identificar um conjunto de atributos do solo, físicos (AF), químicos (AQ) e biológicos $(\mathrm{AB})$ correlacionados com a produtividade do feijoeiro, visando estabelecer as condições de solo mais adequadas ao cultivo desta leguminosa no sistema de produção orgânica. Foram utilizados, conjuntamente, dados de dois experimentos instalados em novembro de 2003 com a cultivar Pérola, um em semeadura direta e outro em preparo convencional do solo, em Santo Antônio de Goiás, GO, em Latossolo Vermelho distrófico, no delineamento de blocos ao acaso, com quatro repetições. Os tratamentos consistiram das plantas de cobertura crotalária, guandu, mucuna-preta, sorgo vassoura e pousio. Foram realizadas amostragens de solo na camada de 0,00-0,10 m, em 2007, para determinação dos AF, AQ e AB. A produtividade apresentou correlação linear positiva com a porcentagem de agregados com diâmetro maior que $2 \mathrm{~mm}$ (AGR), diâmetro médio ponderado dos agregados, carbono da biomassa microbiana (CBM) e quociente microbiano, e negativa com o quociente metabólico, respiração basal e teor de cobre disponível. Pela análise de regressão linear múltipla conclui-se que os atributos do solo que melhor explicaram, de maneira conjunta, a produtividade, foram AGR, CBM e teor de matéria orgânica.
\end{abstract}

Palavras-chave: Phaseolus vulgaris L., semeadura direta, agregação do solo, carbono da biomassa microbiana, matéria orgânica

\section{Correlation between common bean yield under organic production and soil attributes}

\begin{abstract}
This study aimed to identify a set of soil attributes, chemical (CA), physical (PA), and biological (BA), correlated to common bean grain yield in order to establish the most adequate soil conditions to cultivate this legume under organic production system. Data from two experiments installed in November 2003 with cultivar Pérola was used, one under no-tillage and the another in conventional tillage, in Santo Antônio de Goiás, GO, in an Oxisol, in a randomized block design, with four replications. The treatments consisted of cover crops sunn hemp, pigeon pea, velvet bean, sorghum, and fallow. Samples were taken from soil layer of $0-0.10 \mathrm{~m}$ in 2007 for determination of CA, PA, and BA. Grain yield showed positive linear correlation with the percentage of aggregates with a diameter greater than $2 \mathrm{~mm}$ (AGR), mean weighted diameter of aggregates, microbial biomass carbon $(\mathrm{MBC})$ and microbial quotient, and negative one with the basal respiration, metabolic quotient and soil copper content. Based on multiple regression analysis, AGR, MBC and soil organic matter were the soil attributes that together better explained grain yield.
\end{abstract}

Key words: Phaseolus vulgaris L., no-tillage, soil aggregation, microbial biomass carbon, soil organic matter 


\section{INTRODUÇÃO}

O feijoeiro comum (Phaseolus vulgaris L.) é cultivado no Brasil o ano todo, em ecossistemas subtropical e tropical como Cerrado, Mata Atlântica e Semiárido, nos mais variados arranjos de plantas inter e intraespecíficos, em três safras: "das águas" e "da seca" em todos os estados da federação, e "de inverno", com irrigação concentrada nas Regiões Centro-Oeste, Sudeste e Oeste da Bahia, o que garante uma oferta constante do produto para um consumo interno, regionalmente exigente quanto à cor e forma dos grãos (Peloso et al., 2008).

É um produto que envolve aproximadamente 2 milhões de produtores dispersos no País, com $64 \%$ da produção envolvendo a agricultura familiar, em estratos de área inferiores a 5 hectares. Os sistemas produtivos de feijoeiro comum variam desde o menos tecnificado até o de mais alta tecnologia, obtendo-se uma produtividade média de $950 \mathrm{~kg} \mathrm{ha}^{-1}$ nas três safras. As safras "das águas" e "da seca" são conduzidas essencialmente por pequenos produtores que utilizam alto índice de mãode-obra familiar e baixo nível tecnológico enquanto a "de inverno" é produzida no âmbito empresarial, com elevado nível tecnológico (Peloso et al., 2008).

Com o interesse cada vez maior dos agricultores no sistema de produção orgânica, especialmente dos produtores familiares visando ao aumento da rentabilidade e à melhoria da qualidade de vida no meio rural, além da preservação da capacidade produtiva do solo a longo prazo é necessário gerar informações sobre a contribuição de práticas agrícolas na manutenção da qualidade do solo e na produtividade do feijoeiro neste sistema de produção. Entre as práticas agrícolas com tal finalidade se destacam o preparo do solo e o uso de plantas de cobertura.

Atualmente, são conhecidos efeitos isolados de diferentes manejos e culturas de cobertura nos atributos físicos, químicos e biológicos do solo. Entretanto existem, no solo, diversas interrelações entre esses atributos que controlam os processos e os aspectos relacionados à sua variação no tempo e no espaço, de maneira que qualquer alteração no solo pode alterar diretamente sua estrutura e sua atividade biológica e, consequentemente, sua fertilidade, com reflexos na sua qualidade e na produtividade das culturas (Carneiro et al., 2009). Diante disto, a avaliação conjunta desses atributos é importante para o melhor manejo do solo e das culturas, visando à sustentabilidade dos sistemas agrícolas.

Estudos de correlação entre atributos do solo, especialmente os físicos, e produtividade do feijoeiro no sistema de produção convencional têm sido realizados. Megda et al. (2008) constataram, em Latossolo Vermelho distroférrico, correlação linear positiva entre a macroporosidade e negativa entre a microporosidade na camada de $0-0,10 \mathrm{~m}$ e a produtividade do feijoeiro. Nesta mesma cultura Santos et al. (2005) não encontraram, em Latossolo Vermelho distroférrico típico argiloso, com valores médios da resistência do solo à penetração (RP) variando de 1,3 a 3,4 MPa, correlação entre RP e produtividade. Lima et al. (2010) verificaram, contudo, em Argissolo Vermelho distrófico arênico, que a produtividade do feijoeiro foi influenciada por este atributo do solo e indicaram o valor de $1,7 \mathrm{MPa}$ como limitante ao crescimento e à produtividade. As máximas produtividades foram obtidas com valores de RP entre 1,2 e 1,3 MPa. Por sua vez, Roque et al. (2008) constataram, em Latossolo Vermelho distroférrico típico, a produtividade do feijoeiro apresentou baixa correlação com RP e que valores limitantes à produtividade são superiores a $2 \mathrm{MPa}$.

Devido à inter-relação entre os atributos do solo torna-se difícil estabelecer relações de causa e efeito entre atributos isolados e que a produtividade do feijoeiro. Desta maneira buscou-se, com este trabalho, identificar um conjunto de atributos do solo, físicos, químicos e biológicos, correlacionados com a produtividade do feijoeiro visando estabelecer as condições de solo mais adequadas ao cultivo dessa leguminosa no sistema de produção orgânica.

\section{MATERIAL E MÉTODOS}

O trabalho foi conduzido na Fazenda Capivara da Embrapa Arroz e Feijão, localizada no município de Santo Antônio de Goiás, GO, compreendida entre as coordenadas $16^{\circ} 31^{\prime} 18^{\prime \prime}$ $\mathrm{S}, 49^{\circ} 18^{\prime} 45^{\prime}$ ' W, $16^{\circ} 31^{\prime} 18^{\prime \prime} \mathrm{S}, 49^{\circ} 16^{\prime} 07^{\prime}$ 'W, $16^{\circ} 29^{\prime} 02^{\prime \prime} \mathrm{S}$, $49^{\circ} 16^{\prime} 07^{\prime \prime} \mathrm{W}, 16^{\circ} 29^{\prime} 02^{\prime \prime} \mathrm{S}$ e $49^{\circ} 18^{\prime} 45^{\prime \prime} \mathrm{W}$, e com altitude média de $823 \mathrm{~m}$. O clima, conforme classificação de Köppen, é Aw, tropical de savana, megatérmico. O regime pluvial é bem definido com período chuvoso de outubro a abril e seco de maio a setembro, com precipitação média anual de $1485 \mathrm{~mm}$ (Silva et al., 2010). O solo do local é um Latossolo Vermelho distrófico, de textura franco-argilosa, com $410 \mathrm{~g} \mathrm{~kg}^{-1} \mathrm{de}$ areia, $270 \mathrm{~g} \mathrm{~kg}^{-1}$ de silte e $320 \mathrm{~g} \mathrm{~kg}^{-1}$ de argila, na camada de 0,00-0,20 $\mathrm{m}$. Antes da implantação dos experimentos foram aplicados, em toda a área e incorporados com grade aradora, $1.620 \mathrm{~kg}$ $\mathrm{ha}^{-1}$ de fosfato natural Arad $\left(33 \%\right.$ de $\left.\mathrm{P}_{2} \mathrm{O}_{5}\right)$ e $2.000 \mathrm{~kg} \mathrm{ha}^{-1} \mathrm{de}$ calcário. A vegetação original da área experimental era do tipo Cerradão e vinha sendo cultivada no sistema convencional de preparo do solo (gradagens aradora e niveladora) com a rotação milho e soja.

Em novembro de 2003 foram instalados dois experimentos com a cultura do feijão das águas, e conduzidos segundo os preceitos da produção orgânica. Um experimento foi conduzido em semeadura direta e no outro foi feito o preparo convencional do solo com grades aradora e niveladora operando até 0,10 $0,15 \mathrm{~m}$ de profundidade. Em todos os experimentos foram comparadas, no delineamento de blocos ao acaso, com quatro repetições, as culturas de cobertura: crotalária (Crotalaria juncea), guandu (Cajanus cajan (L.) Millsp), mucuna-preta (Mucuna aterrima), sorgo vassoura (Sorgum technicum) e pousio (vegetação espontânea). A vegetação espontânea era constituída basicamente de picão preto (Bidens pilosa), capim pé-de-galinha (Eleusine indica) e leiteiro (Euphorbia heterophylla) com menores ocorrências de braquiária (Brachiaria decumbens), corda de viola (Ipomoea grandifolia), caruru (Amaranthus deflexus), erva de santa Luzia (Chamaisice viridis L.), trapoeraba (Commelina benghalensis), mentrasto (Ageratum conyzoides), beldroega (Portulaca oleracea), guanxuma (Sida cordifolia) e Maria pretinha (Solanum americanum Mill).

As culturas de cobertura foram semeadas em abril de cada ano e conduzidas no sistema de semeadura direta. Por ocasião da semeadura do feijão foram manejadas com rolo-faca e 
deixadas sobre o solo (semeadura direta) ou incorporadas (preparo convencional). Elas foram semeadas sem adubação no espaçamento de $0,45 \mathrm{~m}$ entre linhas, utilizando-se 60 sementes por metro de crotalária, guandu e sorgo e 20 sementes por metro de mucuna. O feijoeiro (Phaseolus vulgaris L.) cv. Pérola foi semeado em novembro, no mesmo espaçamento, com 16 sementes por metro, também sem adubação. A área das parcelas com feijão era de $27,00 \mathrm{~m}^{2}(2,70 \times 10,00 \mathrm{~m})$.

Em novembro de 2007 foi realizada amostragem de solo para análises física, química e biológica, na camada de 0-0,10 m de cada parcela dos dois experimentos cujos dados obtidos nesses experimentos foram usados em conjunto para correlações com a produtividade. Os atributos físicos avaliados foram densidade do solo, determinada pelo método do anel volumétrico, porosidade total (PT), pela relação entre a densidade do solo e a densidade de partículas determinada pelo método do balão volumétrico, microporosidade, considerada igual à quantidade de água retida pelo solo na tensão de $6 \mathrm{kPa}$, macroporosidade (MAP), pela diferença entre porosidade total e microporosidade, diâmetro médio ponderado dos agregados (DMP), determinado via úmida, porcentagem de agregados com diâmetro maior que $2 \mathrm{~mm}$, em que as análises foram realizadas segundo EMBRAPA (1997), índice S (Dexter, 2004) e resistência do solo à penetração, determinada com penetrômetro de impacto (Stolf et al., 1983).

Os atributos químicos avaliados foram: o teor de matéria orgânica, determinado pelo método de Walkley \& Black, o pH do solo e os teores de $\mathrm{P}, \mathrm{K}^{+}, \mathrm{Ca}^{2+}, \mathrm{Mg}^{2+}, \mathrm{Cu}^{2+}, \mathrm{Zn}^{2+}, \mathrm{Fe}^{3+}, \mathrm{Mn}^{2+}$, $\mathrm{H}^{+}+\mathrm{Al}^{3+}$, e calculadas a capacidade de troca de cátions a $\mathrm{pH} 7$ (CTC) e a saturação por bases (V). $\mathrm{O} \mathrm{pH}$ foi determinado em água. $\mathrm{O}$ fósforo e o potássio foram extraídos com a solução de Mehlich $1\left(\mathrm{HCl}\right.$ a $0,5 \mathrm{~N}+\mathrm{H}_{2} \mathrm{SO}_{4}$ a $\left.0,025 \mathrm{~N}\right)$ e determinados em colorímetro e fotômetro de chama, respectivamente. $\mathrm{O} \mathrm{Ca}^{2+}$ e o $\mathrm{Mg}^{2+}$ foram extraídos em $\mathrm{KCl}$ a $1 \mathrm{~N}$ e determinados por titulação de EDTA. Os micronutrientes foram determinados em espectrofotômetro de absorção atômica utilizando-se o extrator Mehlich $1 . \mathrm{O} \mathrm{H}^{+}+\mathrm{Al}^{3+}$ foi determinado por titulometria, através da solução de acetato de cálcio $1 \mathrm{~N}$ a pH 7 para sua extração. As análises laboratoriais foram realizadas de acordo com EMBRAPA (1997).

Os atributos biológicos avaliados foram carbono orgânico total do solo (COT), determinado pelo método de Walkley \& Black (EMBRAPA, 1997), carbono (CBM) da biomassa microbiana, determinado pelo método da fumigação-extração proposto por Vance et al. (1987), respiração basal do solo (RBS), determinada pela quantificação do $\mathrm{CO}_{2}$ liberado durante a incubação do solo em sistema fechado (Jenkinson \& Powlson, 1976) e quocientes metabólico $\left(\mathrm{qCO}_{2}\right)$, obtido pela relação entre RBS e CBM, e microbiano (qMIC) obtido pela relação entre CBM e COT (Anderson \& Domsch, 1993).

Para cada atributo estudado e para a produtividade, foram calculados, pela estatística clássica, a média, a mediana, os valores máximo e mínimo, o desvio-padrão e a variância considerando-se os dados obtidos em todas as parcelas dos dois experimentos. Os atributos do solo foram correlacionados individualmente com a produtividade do feijoeiro colhido em fevereiro de $2008 \mathrm{em}$ uma área de $8,1 \mathrm{~m}^{2}$ por parcela, composta de seis linhas de $3 \mathrm{~m}$. Foi realizada também análise de regressão múltipla para verificar os atributos do solo que mais influenciaram de maneira conjunta a produtividade do feijoeiro, para o que se verificou, primeiro, a existência de colinearidade entre os atributos de solo eliminando-se aqueles que apresentaram correlações maiores que $85 \%$. Por meio deste processo os atributos PT, MAP, DMP, S, V, Zn, COT, $\mathrm{qCO}_{2}$ e qMIC foram excluídos. A análise de regressão múltipla foi aplicada considerando-se os demais atributos do solo enquanto o resíduo foi analisado com a intuito de se verificar se a distribuição era normal, por meio do gráfico "Q-Q plot", que compara o quantil amostral versus o quantil esperado sob normalidade, e do teste de normalidade de Shapiro-Wilk. Os valores residuais padronizados e os valores observados foram plotados para verificar a ausência de autorregressão e variância de erros constante. Após esses procedimentos aplicou-se o método "stepwise" tendo-se adotado, como critério, a supressão de variáveis - BIC (Bayesian information criterion). Para executar os procedimentos descritos anteriormente utilizou-se o programa estatístico R (R Development Core Team, 2011).

\section{RESUlTADOS E DISCUSSÃO}

A densidade do solo apresentou valor médio de $1,33 \mathrm{Mg}$ $\mathrm{m}^{-3}$ e mediana de $1,34 \mathrm{Mg} \mathrm{m}^{-3}$ (Tabela 1) valores abaixo da densidade considerada crítica para solos franco-argilosos, que se situa entre 1,40 e 1,50 $\mathrm{Mg} \mathrm{m}^{-3}$ (Reichert et al., 2003); já o valor máximo observado se manteve entre esses dois limites.

O valor mínimo da porosidade total foi igual a $0,45 \mathrm{~m}^{3} \mathrm{~m}^{-3} \mathrm{e}$ a média e a mediana foram iguais a $0,50 \mathrm{~m}^{3} \mathrm{~m}^{-3}$ (Tabela 1). Silva et al. (2008) constataram, em Latossolo Vermelho argiloso, que valores de porosidade total variando de 0,45 a $0,51 \mathrm{~m}^{3} \mathrm{~m}^{-3}$ não afetaram a produtividade do feijoeiro.

Considerando, de maneira geral, que condições físicas do solo favoráveis ao crescimento das plantas têm sido associadas a uma porosidade de aeração mínima de $0,10 \mathrm{~m}^{3} \mathrm{~m}^{-3}$ (Silva et al., 2008) abaixo da qual a difusão de oxigênio se torna limitante ao funcionamento das raízes, a macroporosidade apresentou média e mediana superiores às deste limite; contudo, o valor mínimo desse atributo ficou abaixo do limite de $0,10 \mathrm{~m}^{3} \mathrm{~m}^{-3}$ (Tabela 1).

O DMP e a porcentagem de agregados com diâmetro maior que $2 \mathrm{~mm}$ apresentaram valores médios de, respectivamente, $5,75 \mathrm{~mm}$ e $60,9 \%$. Segundo Corrêa (2002) sistemas em equilíbrio, com maiores teores de matéria orgânica e boa diversidade e atividade microbiana na massa do solo, apresentam maior agregação do solo.

$\mathrm{O}$ valor médio da resistência do solo à penetração e a mediana ficaram ao redor de $2 \mathrm{MPa}$ (Tabela 1). Valores maiores que este limite têm sido considerados limitantes à produtividade do feijoeiro (Roque et al., 2008). Lima et al. (2010) encontraram que o valor de 1,7 $\mathrm{MPa}$ foi limitante à produtividade do feijoeiro. O valor máximo de RP se situou acima desses limites sinalizando que em algumas situações pode estar havendo problema de compactação do solo, especialmente sob semeadura direta devido ao trânsito de máquinas no solo sem revolvimento; contudo, Santos et al. (2005) não encontraram correlação entre RP e produtividade do feijoeiro na faixa de 1,3 a 3,4 Mpa. 
Tabela 1. Medidas estatísticas descritivas dos atributos do Latossolo Vermelho distrófico estudado e da produtividade do feijoeiro considerando-se, conjuntamente, os diferentes sistemas de preparo e plantas de cobertura

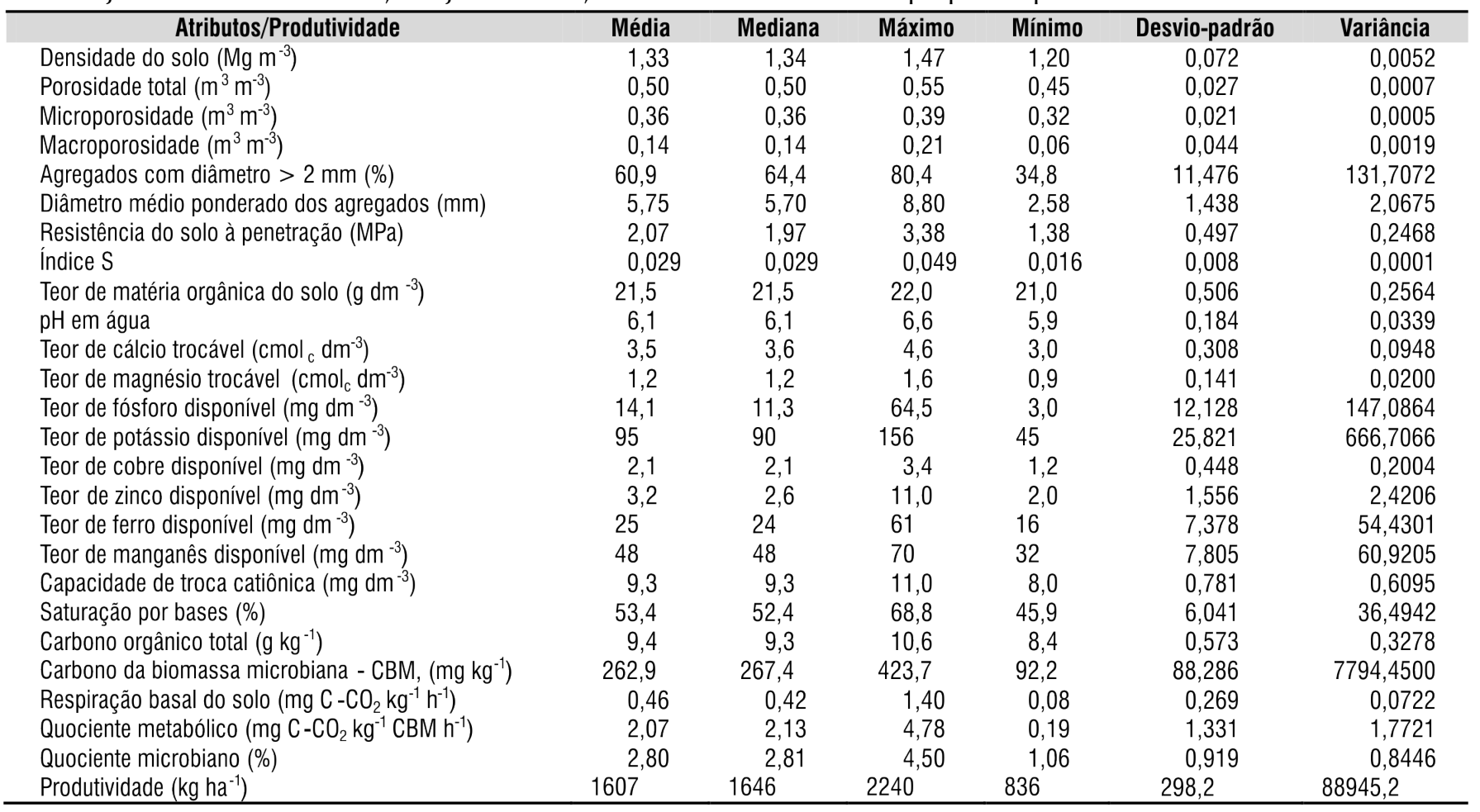

Considerando o limite de $\mathrm{S}<0,025$ para solos degradados fisicamente e $\mathrm{S} \geq 0,045$ para solo com boa qualidade física, como determinado por Andrade \& Stone (2009) para solos de Cerrado, a média e a mediana relativas a este índice se mantiveram entre esses dois limites (Tabela 1). O valor mínimo, por sua vez, ficou abaixo do limite de 0,025 , sinalizando que em algumas situações o uso deste solo para produção agrícola pode degradar sua qualidade física.

Os teores de fósforo e potássio se classificaram, respectivamente, como médio e alto, segundo Souza \& Lobato (2004) considerando-se tanto as médias como as medianas. Com base nos valores mínimos, o $\mathrm{pH}$ se enquadrou como fracamente ácido, o teor de fósforo se classificou como muito baixo e os de potássio e matéria orgânica como médios, assim como a CTC (Tabela 1). Para os demais nutrientes e para a saturação por bases os valores mínimos se enquadraram na classe alta (Souza \& Lobato, 2004).

O CBM apresentou valor médio de $262,9 \mathrm{mg} \mathrm{kg}^{-1} \mathrm{e}$ mediana de $267,4 \mathrm{mg} \mathrm{kg}^{-1}$ (Tabela 1). Para a respiração basal e quociente metabólico esses valores foram, respectivamente, 0,46 e $0,42 \mathrm{mg} \mathrm{C}-\mathrm{CO}_{2} \mathrm{~kg}^{-1} \mathrm{~h}^{-1}$ e 2,08 e $2,81 \mathrm{mg} \mathrm{C}-\mathrm{CO}_{2} \mathrm{~kg}^{-1}$ $\mathrm{CBM} \mathrm{h}^{-1}$. Ditos valores podem ser considerados adequados à obtenção de altas produtividades de feijão. Garcia et al. (2004) obtiveram produtividades de feijão acima de $2000 \mathrm{~kg}$ $\mathrm{ha}^{-1}$ com manejos de solo que propiciaram valores de CBM ao redor de $90 \mathrm{mg} \mathrm{kg}^{-1}$, mesma magnitude do valor mínimo observado neste trabalho, de RBS ao redor de $0,40 \mathrm{mg} \mathrm{C}-\mathrm{CO}_{2}$ $\mathrm{kg}^{-1} \mathrm{~h}^{-1}$ e de qCO2 entre 4,18 e 5,19 mg C-CO $\mathrm{kg}^{-1} \mathrm{CBM} \mathrm{h}^{-1}$. Esses valores de $\mathrm{qCO}_{2}$ se situam próximo do valor máximo observado neste trabalho.

Em condições normais o quociente microbiano varia de 1 a $4 \%$ e valores inferiores a $1 \%$ podem ser atribuídos a algum fator limitante à atividade da biomassa microbiana (Jakelaitis et al., 2008). A média, a mediana e, inclusive, o valor mínimo observado para este quociente, foram superiores a $1 \%$ (Tabela 1) indicando que o sistema de produção orgânico favoreceu a atividade dos micro-organismos, independentemente do preparo do solo e das plantas de cobertura.

A produtividade média foi de $1607 \mathrm{~kg} \mathrm{ha}^{-1} \mathrm{e}$ a mediana de $1646 \mathrm{~kg} \mathrm{ha}^{-1}$ (Tabela 1) valores abaixo da média de Goiás no ano de 2008, na safra "das águas", que foi de $1894 \mathrm{~kg} \mathrm{ha}^{-1}$ (IBGE, 2009) devido, possivelmente, ao maior uso de insumos pelos produtores que não praticam a agricultura orgânica.

O impacto negativo da compactação do solo na produtividade do feijoeiro foi demonstrado por Lima et al. (2010). Realmente se verificou, neste trabalho, a importância de um solo bem estruturado haja vista que as maiores correlações positivas com a produtividade foram verificadas para a porcentagem de agregados com diâmetro maior que $2 \mathrm{~mm}$ e diâmetro médio ponderado dos agregados (Tabela 2).

Pelo fato de não haver mobilização do solo a semeadura direta, em comparação com o preparo convencional, contribui para maior agregação do solo, expressa pela porcentagem de agregados maiores que $2 \mathrm{~mm}$ e pelo diâmetro médio ponderado dos agregados, conforme constatou Corrêa (2002).

O carbono da biomassa microbiana e o quociente microbiano também apresentaram correlação positiva e altamente significativa com a produtividade do feijoeiro (Tabela 2). Maior quantidade de CBM reflete a presença de maior quantidade de matéria orgânica ativa no solo, capaz de manter elevada taxa de decomposição de restos vegetais e, portanto, de reciclar mais nutrientes. Ademais, Cunha et al. (2011a) observaram correlação significativa entre CBM e COT e este último afeta positivamente a qualidade física do solo (Cunha 
Tabela 2. Correlação de Pearson entre os atributos do solo e a produtividade do feijoeiro sob diferentes preparos do solo e plantas de cobertura $(n=40)$

\begin{tabular}{|c|c|c|}
\hline \multirow{2}{*}{ Atributos } & \multicolumn{2}{|c|}{ Correlação } \\
\hline & $r$ & Probabilidade \\
\hline Densidade do solo $\left(\mathrm{Mg} \mathrm{m}^{-3}\right)$ & 0,126 & 0,438 \\
\hline Porosidade total $\left(\mathrm{m}^{3} \mathrm{~m}^{-3}\right)$ & 0,126 & 0,438 \\
\hline Microporosidade $\left(\mathrm{m}^{3} \mathrm{~m}^{-3}\right)$ & 0,152 & 0,348 \\
\hline Macroporosidade $\left(\mathrm{m}^{3} \mathrm{~m}^{-3}\right)$ & 0,153 & 0,346 \\
\hline Agregados com diâmetro > 2 mm (\%) & $0,625^{\star *}$ & 0,00002 \\
\hline Diâmetro médio ponderado dos agregados (mm) & $0,563^{* *}$ & 0,0002 \\
\hline Resistência do solo à penetração (MPa) & 0,147 & 0,364 \\
\hline Índice S & 0,117 & 0,472 \\
\hline Teor de matéria orgânica do solo $\left(\mathrm{g} \mathrm{dm}^{-3}\right)$ & 0,239 & 0,137 \\
\hline pH em água & 0,052 & 0,747 \\
\hline Teor de cálcio trocável $\left(\mathrm{cmol}_{\mathrm{c}} \mathrm{dm}^{-3}\right)$ & 0,051 & 0,755 \\
\hline Teor de magnésio trocável $\left(\mathrm{cmol}_{\mathrm{C}} \mathrm{dm}^{-3}\right)$ & 0,124 & 0,447 \\
\hline Teor de fósforo disponivel $\left(\mathrm{mg} \mathrm{dm}^{-3}\right)$ & 0,207 & 0,200 \\
\hline Teor de potássio disponível (mg dm ${ }^{-3}$ ) & 0,026 & 0,872 \\
\hline Teor de cobre disponível $\left(\mathrm{mg} \mathrm{dm}^{-3}\right)$ & $-0,335^{*}$ & 0,034 \\
\hline Teor de zinco disponível $\left(\mathrm{mg} \mathrm{dm}^{-3}\right)$ & 0,116 & 0,476 \\
\hline Teor de ferro disponível $\left(\mathrm{mg} \mathrm{dm}^{-3}\right)$ & 0,074 & 0,652 \\
\hline Teor de manganês disponível (mg $\mathrm{dm}^{-3}$ ) & 0,049 & 0,764 \\
\hline Capacidade de troca catiônica $\left(\mathrm{mg} \mathrm{dm}^{-3}\right)$ & 0,017 & 0,916 \\
\hline Saturação por bases (\%) & 0,052 & 0,747 \\
\hline Carbono orgânico total $\left(\mathrm{g} \mathrm{kg}^{-1}\right)$ & 0,198 & 0,222 \\
\hline Carbono da biomassa microbiana- CBM, $\left(\mathrm{mg} \mathrm{kg}^{-1}\right)$ & $0,449 * *$ & 0,004 \\
\hline Respiração basal do solo $\left(\mathrm{mg} C-\mathrm{CO}_{2} \mathrm{~kg}^{-1} \mathrm{~h}^{-1}\right)$ & $-0,465^{\star *}$ & 0,002 \\
\hline Quociente metabólico (mg C-CO $\mathrm{kg}^{-1} \mathrm{CBM} \mathrm{h}{ }^{-1}$ ) & $-0,521 * *$ & 0,0006 \\
\hline Quociente microbiano (\%) & $0,414^{\star \star}$ & 0,008 \\
\hline
\end{tabular}

et al., 2011b). Garcia et al. (2004) observaram relação linear positiva entre $\mathrm{CBM}$ e produtividade do feijoeiro.

$\mathrm{O}$ quociente microbiano reflete o padrão do aporte de matéria orgânica do solo, a eficiência da conversão do carbono microbiano, as perdas de carbono do solo e a estabilização do carbono orgânico pelas frações minerais do solo. Assim, qMIC indica se o conteúdo de carbono se mantém estável ou varia de acordo com as condições impostas ao sistema (Tótola \& Chaer, 2002). Como discutido antes, o valor mínimo observado para este quociente foi superior a $1 \%$ (Tabela 1 ) indicando que as condições do solo não foram limitantes à atividade da biomassa microbiana.

O quociente metabólico apresentou correlação negativa com a produtividade do feijoeiro (Tabela 2). Valores elevados do quociente metabólico são indicativos de ecossistemas submetidos a alguma condição de estresse ou distúrbio (Anderson \& Domsch, 1993). Silva et al. (2007) observaram maior $\mathrm{qCO}_{2}$ no solo sob preparo convencional do que em semeadura direta. O preparo convencional do solo promove rompimento dos macro e microagregados e, em consequência, torna a matéria orgânica mais suscetível ao ataque microbiano o que aumenta a taxa de mineralização e liberação de $\mathrm{CO}_{2}$ para a atmosfera (Ferreira et al., 2010).

A respiração basal também apresentou correlação negativa com a produtividade do feijoeiro (Tabela 2). A maior liberação de $\mathrm{CO}_{2}$ está associada, comumente, à maior atividade biológica que, por sua vez, está relacionada diretamente com a quantidade de carbono lábil existente no solo. Entretanto, a interpretação dos resultados da atividade biológica deve ser feita com critério uma vez que elevados valores de respiração nem sempre indicam condições desejáveis: a curto prazo pode significar liberação de nutrientes para as plantas e, a longo prazo, perda de carbono orgânico do solo para a atmosfera (Silva et al., 2007).

Segundo Balota et al. (1998) o tipo de manejo do solo pode selecionar uma população microbiana mais eficiente que, por sua vez, apresente uma perda menor de carbono via respiração, fato importante na manutenção do teor de carbono do solo. Nos experimentos considerados a RBS foi menor sob semeadura direta (Cunha et al., 2011a). Este sistema, tal como a rotação de culturas e a cobertura vegetal permanente e a proteção contínua da superfície do solo, estimulam a atividade microbiana e sua atuação sobre os processos bioquímicos conduzindo o agroecossistema a um novo equilíbrio, menos dependente de insumos químicos e mais próximo da sustentabilidade.

$\mathrm{O}$ teor de cobre se correlacionou negativamente com a produtividade do feijoeiro (Tabela 2). Teores elevados de cobre podem afetar negativamente os micro-organismos do solo (Antoniolli et al., 2010) alterando sua funcionalidade e diversidade, bem como a produção de biomassa. Como o CBM apresentou correlação positiva com a produtividade do feijoeiro, o efeito deletério do cobre sobre os micro-organismos pode explicar sua correlação negativa com a produtividade. Marsola et al. (2005) constataram, em Cambissolo, redução na produção de massa seca do feijoeiro com o aumento da dose de cobre

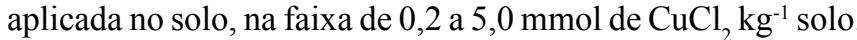

Considerando todos os atributos do solo verificou-se que os que melhor explicaram, de maneira conjunta, a produtividade do feijoeiro usando o método "stepwise", foram a porcentagem de agregados com diâmetro maior que $2 \mathrm{~mm}$, carbono da biomassa microbiana e teor de matéria orgânica do solo, sendo ajustada a seguinte equação de regressão linear múltipla:

$$
\begin{array}{rlr}
\mathrm{PROD} & =-2475,94+13,25 \mathrm{AGR} * *+1,17 \mathrm{CBM}^{* *}+ \\
& +138,09 \mathrm{MO}^{*}, & \mathrm{R}^{2}=0,49 * *
\end{array}
$$

em que:

PROD - produtividade de grãos do feijoeiro $\left(\mathrm{kg} \mathrm{ha}^{-1}\right)$

AGR - porcentagem de agregados com diâmetro maior que $2 \mathrm{~mm}$

CBM - carbono da biomassa microbiana $\left(\mathrm{mg} \mathrm{kg}^{-1}\right)$

$\mathrm{MO}$ - teor de matéria orgânica do solo $\left(\mathrm{g} \mathrm{dm}^{-3}\right)$

Sabendo-se que a produtividade de qualquer cultura é o resultado da interação de fatores climáticos, da planta e do solo, a obtenção de um conjunto de atributos do solo que explique $49 \%$ dela, é altamente satisfatória.

Desta maneira, manejos que favorecem a agregação do solo, como a semeadura direta, uma vez que o preparo do solo conduz ao fracionamento dos agregados maiores em unidades menores e que aportem matéria orgânica e favoreçam a atividade dos micro-organismos do solo resultarão, provavelmente, em maior produtividade do feijoeiro. Teores mais elevados de CBM e de matéria orgânica têm sido verificados em solos com ausência de revolvimento (Silva et al., 2007; Jakelaitis et al., 2008). Corrêa (2002) encontrou correlação entre matéria orgânica e a porcentagem de agregados com diâmetro maior que $2 \mathrm{~mm}$. A presença de maior quantidade de matéria orgânica ativa no solo, capaz de manter elevada taxa de decomposição de restos 
vegetais e, portanto, de reciclar mais nutrientes, reflete em maior teor de carbono da biomassa microbiana. Este atributo representa a parte viva e mais ativa da matéria orgânica e é mais sensível ao preparo do solo que a parte morta, como observaram Carneiro et al. (2009).

\section{Conclusões}

1. A agregação do solo, expressa como porcentagem de agregados com diâmetro maior que $2 \mathrm{~mm}$ e diâmetro médio ponderado dos agregados, o teor de carbono da biomassa microbiana e o quociente microbiano, são os atributos do solo que favoreceram a produtividade do feijoeiro.

2. Atributos do solo que indicam alguma condição de estresse, como o quociente metabólico e a respiração basal, além do teor de cobre disponível no solo afetaram, negativamente, a produtividade do feijoeiro.

3. Na análise conjunta dos atributos do solo a combinação da porcentagem de agregados com diâmetro maior que $2 \mathrm{~mm}$, com o teor de carbono da biomassa microbiana e com a matéria orgânica do solo, apresentou o maior coeficiente de correlação com a produtividade do feijoeiro.

\section{LITERATURA CITADA}

Anderson, J. P E.; Domsch, K. H. The metabolic quotient $\left(\mathrm{qCO}_{2}\right)$ as a specific activity parameter to asses the effects of environmental conditions, such as $\mathrm{pH}$, on the microbial biomass of forest soils. Soil Biology \& Biochemistry, v.25, p.393-395, 1993.

Andrade, R. da S.; Stone, L. F. Índice S como indicador da qualidade física de solos do cerrado brasileiro. Revista Brasileira de Engenharia Agrícola e Ambiental, v.13, p.382388, 2009.

Antoniolli, Z. I.; Santos, L. C. dos; Lupatini, M.; Leal, L. T.; Schirmer, G. K.; Redin, M. Efeito do cobre na população de bactérias e fungos do solo, na associação micorrízica e no cultivo de mudas de Eucalyptus grandis W. Hill ex Maiden, Pinus elliottii Engelm e Peltophorum dubium (Sprengel) Taubert. Ciência Florestal, v.20, p.419-428, 2010.

Balota, E. L.; Colozzi-Filho, A.; Andrade, D. S.; Hungria, M. Biomassa microbiana e sua atividade em solos sob diferentes sistemas de preparo e sucessão de culturas. Revista Brasileira de Ciência do Solo, v.22, p.641-649, 1998.

Carneiro, M. A. C.; Souza, E. D. de; Reis, E. F. dos, Pereira, H. S.; Azevedo, W. R. de. Atributos físicos, químicos e biológicos de solo de Cerrado sob diferentes sistemas de uso e manejo. Revista Brasileira de Ciência do Solo, v.33, p.147-157, 2009.

Corrêa, J. C. Efeito de sistemas de cultivo na estabilidade de agregados de um Latossolo Vermelho-Amarelo em Querência, MT. Pesquisa Agropecuária Brasileira, v.37, p.203-209, 2002.

Cunha, E. Q. da; Stone, L. F.; Ferreira, E. P. de B.; Didonet, A.D.; Moreira, J.A.A.; Leandro, W. M. Sistemas de preparo do solo e culturas de cobertura na produção orgânica de feijão e milho. II - Atributos biológicos do solo. Revista Brasileira de Ciência do Solo, v.35, p.603-611, 2011a.
Cunha, E. Q. da; Stone, L. F.; Moreira, J. A. A.; Ferreira, E.P. de B.; Didonet, A. D.; Leandro, W. M. Sistemas de preparo do solo e culturas de cobertura na produção orgânica de feijão e milho. I - Atributos físicos do solo. Revista Brasileira de Ciência do Solo, v.35, p.589-602, 2011 b.

Dexter, A. R. Soil physical quality. Part 1. Theory, effects of soil texture, density, and organic matter, and effects on root growth. Geoderma, v.120, p.201-214, 2004.

EMBRAPA - Empresa Brasileira de Pesquisa Agropecuária. Centro Nacional de Pesquisa de Solos. Manual de métodos de análise de solos. 2.ed. Rio de Janeiro: Embrapa CNPS, 1997. 212p. Documentos, 1.

Ferreira, E. P. B.; Santos, H. P; Costa, J. R.; De-Polli, H.; Rumjanek, N. G. Microbial soil quality indicators under different crop rotations and tillage management. Revista Ciência Agronômica, v.41, p.177-183, 2010.

Garcia, M. R. L.; Mello, L. M. M. de; Cassiolato, A. M. R. Variáveis microbiológicas e produtividade do feijoeiro sob diferentes manejos do solo e calagem. Pesquisa Agropecuária Brasileira, v.39, p.1021-1026, 2004.

IBGE - Instituto Brasileiro de Geografia e Estatística. Levantamento sistemático da produção agrícola. Rio de Janeiro: IBGE, v.21, p.1-79, 2009.

Jakelaitis, A.; Silva, A. A. da; Santos, J. B. dos; Vivian, R. Qualidade da camada superficial de solo sob mata, pastagens e áreas cultivadas. Pesquisa Agropecuária Tropical, v.38, p.118-127, 2008.

Jenkinson, D. S.; Powlson, D. S. The effects of biocidal treatments on metabolism in soil. A method for measuring soil biomass. Soil Biology \& Biochemistry, v.8, p.209-213, 1976.

Lima, C. L. R. de; Reinert, D. J.; Reichert, J. M.; Suzuki, L. E. A. S. Produtividade de culturas e resistência à penetração de Argissolo Vermelho sob diferentes manejos. Pesquisa Agropecuária Brasileira, v.45, p.89-98, 2010.

Marsola, T.; Miyazawa, M.; Pavan, M. A. Acumulação de cobre e zinco em tecidos do feijoeiro em relação com o extraído do solo. Revista Brasileira de Engenharia Agrícola e Ambiental, v.9, p.92-98, 2005.

Megda, M. M.; Carvalho, M. de P.; Vieira, M. X.; Andreotti, M.; Pereira, E.C. Correlação linear e espacial entre a produtividade do feijão e a porosidade de um Latossolo Vermelho de Selvíria (MS). Revista Brasileira de Ciência do Solo, v.32, p.781-788, 2008.

Peloso, M. J. del; Wander, A. E.; Stone, L. F. Feijão comum: impulsionando a produção e a produtividade de grãos na agricultura brasileira. In: Albuquerque, A. C. S.; Silva, A. G. da eds. Agricultura tropical: quatro décadas de inovações tecnológicas, institucionais e políticas. Brasília: Embrapa Informação Tecnológica, 2008. p.219-233.

$\mathrm{R}$ Development Core Team. R: A language and environment for statistical computing. $R$ foundation for statistical computing, (2011). Vienna, Austria. <http://www.R-project.org>. 25 Jan 2011.

Reichert, J. M.; Reinert, D. J.; Braida, J. A. Qualidade dos solos e sustentabilidade de sistemas agrícolas. Ciência Ambiental, v.27, p.29-48, 2003. 
Roque, M. W.; Matsura, E. E.; Souza, Z. M. de; Bizari, D. R.; Souza, A.L. de. Correlação linear e espacial entre a resistência do solo ao penetrômetro e a produtividade do feijoeiro irrigado. Revista Brasileira de Ciência do Solo, v.32, p.1827-1835, 2008.

Santos, P. A. dos; Carvalho, M. de P.; Freddi, O. da S.; Kitamura, A. E.; Freitag, E. E.; Vanzela, L. S. Correlação linear e espacial entre o rendimento de grãos do feijoeiro e a resistência mecânica à penetração em um Latossolo Vermelho distrófico. Revista Brasileira de Ciência do Solo, v.29, p.287-295, 2005.

Silva, M. B. da; Kliemann, H. J; Silveira, P. M. da; Lanna, A. C. Atributos biológicos do solo sob influência da cobertura vegetal e do sistema de manejo. Pesquisa Agropecuária Brasileira, v.42, p.1755-1761, 2007.

Silva, M. G. da; Arf, O.; Alves, M. C.; Buzetti, S. Sucessão de culturas e sua influência nas propriedades físicas do solo e na produtividade do feijoeiro de inverno irrigado, em diferentes sistemas de manejo do solo. Bragantia, v.67, p.335-347, 2008.
Silva, S. C. da; Heinemann, A. B.; Paz, R. L. F.; Amorim, A. de O. Informações meteorológicas para pesquisa e planejamento agrícola, referentes ao ano de 2009, do município de Santo Antônio de Goiás, GO. Santo Antônio de Goiás: Embrapa Arroz e Feijão, 2010. 32p. Documentos, 256.

Souza, D. M. G.; Lobato, E. eds. Cerrado: correção do solo e adubação. 2.ed. Brasília: Embrapa Informação Tecnológica, 2004. 416p.

Stolf, R.; Fernandes, J.; Furlani Neto, V. L. Penetrômetro de impacto, IAA/Planalsucar-Stolf: Recomendações para o seu uso. STAB, v.1, p.18-23, 1983.

Tótola, M. R.; Chaer, G. M. Microorganismos e processos microbiológicos como indicadores de qualidade dos solos. In: Alvares, V. H.; Schaefer, C. E. G. R.; Barros, N. F.; Mello, J. W. V.; Costa, L. M. (ed.) Tópicos em Ciência do Solo. Viçosa: Sociedade Brasileira de Ciência do Solo, 2002. v.2, p.195-276.

Vance, E. D.; Brookes, P. C.; Jenkinson, D. S. An extraction method for measuring soil microbial biomass C. Soil Biology and Biochemistry, v.19, p.703-707, 1987. 